\title{
Deposition of Polymer Sensor Films on SAW Surface by Electrospraying Technology
}

\author{
Krzysztof JASEK $^{(1)}$, Mateusz PASTERNAK ${ }^{(2)}$, Michał GRABKA ${ }^{(1)}$ \\ Sławomir $\operatorname{NEFFE}^{(1)}$, Dariusz ZASADA ${ }^{(3)}$ \\ (1) Institute of Chemistry, Military University of Technology \\ S. Kaliskiego 2, 00-908 Warszawa, Poland \\ ${ }^{(2)}$ Institute of Radioelectronics, Military University of Technology \\ S. Kaliskiego 2, 00-908 Warszawa, Poland; e-mail: mateusz.pasternak@wat.edu.pl \\ (3) Chair of Advanced Materials and Technologies, Military University of Technology \\ S. Kaliskiego 2, 00-908 Warszawa, Poland
}

(received April 29, 2017; accepted June 12, 2017)

\begin{abstract}
One of the most important problems with regard to the Surface Acoustic Wave (SAW) gas sensors technology is the deposition of chemosensitive films exhibiting desirable chemical and physical properties. The electrospraying technology seems to be a very promising method of the film deposition in this case. It allows the chemosensitive layers to be obtained out of almost any chemicals and their mixtures in a controllable way. The process gives the possibility to generate specific films with properties unattainable if other methods were to be applied. For example, it allows to deposit solutions of polymers and suspensions of solids in polymer solutions which can degrade in the process of thermal evaporation deposition.

The paper describes the results of experiments with electrospraying technique in order to obtain Nafion ${ }^{\circledR}$ films. The influence of the process parameters on film sensitivity has been studied.
\end{abstract}

Keywords: Surface Acoustic Wave (SAW) gas sensors; deposition of chemosensitive films; Nafion ${ }^{\circledR}$ films.

\section{Introduction}

Surface acoustic wave (SAW) devices, such as delay lines or resonators, allow to construct a wide range of sensors for the detection of a great variety of physical quantities. Acoustic wave propagating towards the surface of the piezoelectric substrate is very sensitive to changes of mechanical and electrical conditions at the surface. The change can be induced using an interfacial layer (or a multilayer structure) as well. It has the ability to transform certain physical quantity under detection to a change of mechanical or electrical conditions at the surface of the SAW substrate region. Many kinds of SAW sensors operate basing on the interfacial layer. One can mention here the SAW-based magnetic field sensors, ultra violet sensors, and, above all, SAW systems for detection of various vapours and gases (Devkota et al., 2017).

Apart from the typical electronical and physical problems associated with the SAW sensor technology, two key problems are still perceived as the most im- portant ones. The first one is related to the quest for the chemosensitive materials used for detection films, while the second is connected with the precise deposition of the film in the specific form and at the specific area of the substrate. Because of different kinds of material structures, there are many deposition techniques and a lot of them are a work in progress.

Taking into consideration the structure and physicochemical properties, in general, the chemo-sensitive layers can be classified into: metals, metaloxides, polymers, organic semiconductors, and others. Metallic layers are used first of all for hydrogen (VIESPE, GRIGORIU, 2013; VANOTTI et al., 2015) and mercury detection (JASEK et al., 2012). The hydrogen is absorbed by palladium and its alloys forming hydrides, while mercury forms amalgam with gold. Metaloxides are usually semiconductors, such as $\mathrm{SnO}_{2}, \mathrm{ZnO}, \mathrm{WO}_{3}$, $\mathrm{TiO}_{2}$ etc. (RAJ et al., 2013; LuO et al., 2014; RAJ, 2012; JAKUBIK et al., 2009). They are used in sensors which utilise catalytic oxidation for the detection of vapours of flammable substances. Polymers are a very 
large group of structurally different compounds characterised by a wide range of physical and chemical properties. They may be applied for the detection of many vapours and gases (HARSANYI, 1995; ADHIKARI, MAJUMDAR, 2004). There is a large choice when selecting polymers, and even they can be designed for specific sensor purposes. Among the organic semiconductors the most common are phtalocyanines and porphyrins, which are used to detect $\mathrm{NO}_{2}$, and volatile organic compounds (VOC, Hassman, Gould, 1992; JAKUBIK et al., 2012; Di NATALE et al., 1998). Other layers, such as organic nitrogen bases $\left(\mathrm{CO}_{2}\right.$ detection, ZHOU et al., 1996), non-metallic conductive compounds, e.g., CdS (LEE et al., 1998) form a separate group which is hard to classify. The basic compounds mentioned above are often bonded to obtain some synergic sensitive properties. There are two main groups of such kinds of hybrids: multilayers and suspensions. The synergy effect in this case increases sensitivity or selectivity of the sensor (JAKUBIK et al., 2009; 2012).

The chemosensitive layer (usually a film), as an interface between the environment and the SAW surface, has to be deposited in the way which ensures its good adhesion, durability, high purity, good uniformity, and homogeneity (composition, morphology). The selected method of the deposition must allow: control of the layer thickness and its structure, precision of placement, it has to exhibit high repeatability and be characterised by simplicity and a low cost. The deposition process should not weaken the SAW transducers' structure or degrade deposited material.

Unfortunately, the method which would fulfil all the requirements mentioned above does not exist. The layer deposition techniques useful in SAW sensors technology can be divided into two main groups: the physical- and the chemical one. Each one has its own advantages and disadvantages. Selection of the specific technology depends on the kind of compounds to be deposited and on the required parameters of the layer.

The physical group includes the application of a liquid solution of a polymer (or other compounds) in a volatile solvent as in the process of: dip-coating, e.g. Langemuir-Blodget method (RoBERTs, 1990), spinoff, painting, and atomisation, which in turn is subdivided into the pneumatic atomisation (ZIMMERMANN et al., 2001), piezoelectric atomisation, or electrospraying (SARKAR et al., 2006). Apart from the methods already listed there are some physical methods applicable to bulk materials, and these include vacuum evaporation: thermal method, electron beam method, and laser ablation (Hassmann, Gould, 1992; KawaleC et al., 2008; PIQUÉ et al., 2003).

As far as chemical methods are concerned, a new chemical compound is created from precursors on the SAW substrate or an existing compound is chemically binding to the substrate. The first group, comprising Chemical Vapour Deposition (CVD) (LA-
MARA et al., 2004) and Atomic Layer Deposition (ALD) (Johnson et al., 1996), uses the gas phase to transport volatile molecules to the surface serving as a substrate. The second group of deposition techniques, called Chemical Solution Deposition or Sol-Gel Processing, uses the liquid phase as the mass transfer media (LuO et al., 2015). These methods enable covalent binding of monolayers or spatial networks of chemical compounds to the substrate (BAin, Whitesides, 1989).

The majority of methods mentioned above do not allow to obtain some specific mixtures, such as of a polymer and a metal, although it is possible to deposit some mixtures from solution. Against such a backdrop, electrospraying technology seems to be a very promising method of film deposition. It enables chemosensitive layers to be obtained of almost any chemicals and their mixtures in a highly controllable manner. The control over the process parameters creates a possibility of depositing specific films with properties almost unattainable if any other method was to be applied. Furthermore, electrospraying is known in fuel cells technology for production of the conductive polymer layers with $\mathrm{Pt}$ loadings for fuel cells cathodes (MARTin et al., 2010a; 2010b; Benítez et al., 2005).

\section{Electrospraying - short overview}

Electrospraying technology has been applied in many fields to produce particles of various compounds. The method works even in normal environmental conditions and its result is the desired morphology of the layer. This is done via selection of a proper solvent or solvent mixture, as well as particle sizes, from the nanoscale up to the microscale.

The process of liquid drop disintegration by electric forces was preliminary studied by Rayleigh (RAYleigh, 1882) who had derived the formula of charged droplet stability threshold (the so-called Rayleigh limit). It states that the drop may break apart into much smaller droplets when Coulomb force overcomes the cohesive force (surface tension) of the drop. This occurs when the total charge of the drop exceeds the value:

$$
Q_{R}=8 \pi \sqrt{\varepsilon \gamma r^{3}},
$$

where $\varepsilon$ is the permittivity of the drop environment, $\gamma$ is the surface tension of the liquid and $r$ is the radius of the drop. Although the theory is still considered valid, the measured limit for various compounds in different experiments turns out to be lower. As the charges are divided into newly issued droplets generation, the breaking process is repeated up to the moment when the droplet charge decreases below the Rayleigh limit. The mechanism of electrical droplet disintegration was then investigated in (OGATA et al., 
2010; Fernandez de la Mora, Loscertales, 1994; GAÑ̂́N-CALVO, 1999) among others and it is still studied (e.g. RozhKova et al., 2015).

The formulas resulting from the studies and experiments allow determining key parameters of the process and their dependence on specific physical quantities. According to (GAÑ́n-CALVO, 1999) the final droplet size can be calculated using the following dependence:

$$
d=\alpha \sqrt[6]{\frac{\varphi^{3} \varepsilon \rho}{\pi^{4} \sigma \gamma}},
$$

where $\alpha$ is a constant depending on liquid permittivity, $\varphi$ is the liquid flow rate, $\rho$ and $\sigma$ are liquid density and conductivity, respectively.

The shape of the electrosprayed jet is dependent on the properties of the liquid sprayed and the voltage between the end of a capillary and the target ground plane. The shape change for increased voltage is illustrated in Fig. 1.

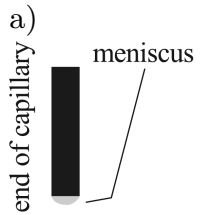

d)

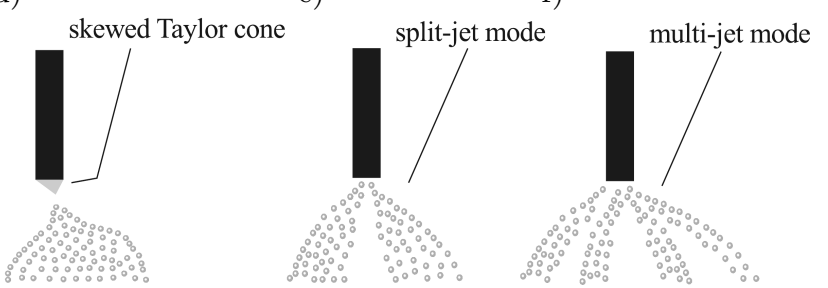

Fig. 1. Electrosprayed jet shape evolution with increasing voltage: a) voltage lower than the Rayleigh limit requirement, b) voltage overcomes the Rayleigh limit, c) threshold voltage of the Taylor cone formation, d) voltage skewed Taylor cone, e) voltage threshold of jet splitting, f) further increase in voltage causes subsequent jets splitting and multi-jet formation.

When a polymer solution is sprayed using the high voltage technology and the polymer has sufficient chain entanglement density then electrospinning rather than electrospraying occurs. Unlike common liquids, after the process, the droplets of a polymer solution undergo additional consolidation and agglomeration processes. The physical mechanisms of this phenomenon were partially described with the Cahn-Hilliard equation, however, there is no satisfactory theory which would allow the final layer morphology to be predicted.

\section{Electrospraying application in SAW sensors technology}

\subsection{Electrospray setup}

The laboratory set to film deposition using electrospraying technology is very simple and does not require special environmental conditions (e.g. vacuum, low humidity, high purity). It consists of a controllable stepper motor, a syringe with a micro-nozzle, and high voltage generator. In order to avoid an excessive dispersion of the electric field, a ring with certain potential was applied. The scheme of the set is presented in Fig. 2.

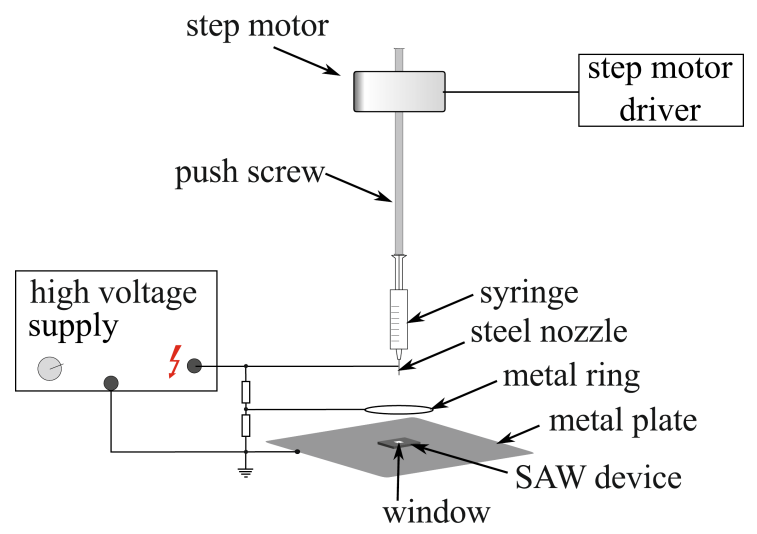

Fig. 2. Schematic view of the laboratory set.

As was already mentioned, the shape of the electrosprayed jet depends on the sprayed liquid properties and on the voltage between the end of the capillary and the target ground plane. The tests were performed for voltages ranging from $1 \mathrm{kV}$ to $10 \mathrm{kV}$ and the distance of the needle tip to the ground plate from $1 \mathrm{~cm}$ to $5 \mathrm{~cm}$. The liquids sprayed were water, ethyl alcohol, and their mixtures. The changes of the jet shape for increased voltage are illustrated in Fig. 3. These expe- a)

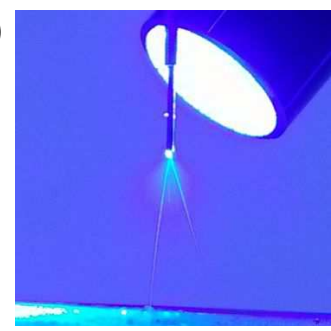

b)

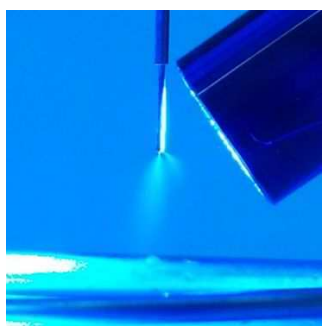

c)

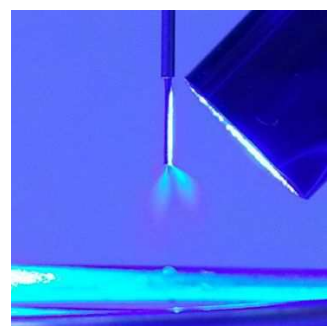

d)

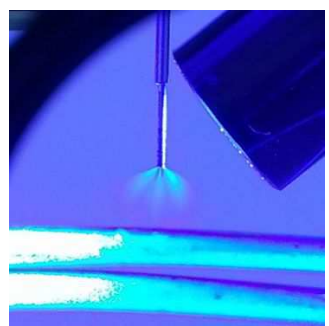

Fig. 3. Images of the electrospraying jets of water for: a) $2.5 \mathrm{kV}$, b) $5 \mathrm{kV}$, c) $7.5 \mathrm{kV}$, d) $10 \mathrm{kV}$. 
riments enabled the selection of the optimal parameters to conduct Nafion ${ }^{\circledR}$ deposition on SAW substrate.

The images shown in Fig. 3a-d correspond to illustrations presented in Fig. 1b-f.

\subsection{Nafion ${ }^{\circledR}$ deposition}

For the measurements, the two-port RS197 SAW quartz resonators were applied. The structure of the resonator, as well as its parameters and characteristics, are described in (Soluch, 2008). The devices are designed just for the sensor purposes and have a $4 \mathrm{~mm}$ gap between interdigital transducers, and they are suitable for sensitive film deposition.

First attempts of polymer deposition on quartz SAW substrate were performed using direct current; however, they were not entirely successful. Due to a build-up of surface charge, the insulating substrate was repulsing the charged droplets which were settling on grounded electrodes. To eliminate the surface charge, an alternating current of frequency in order of $3 \mathrm{kHz}$ was added to the constant component. Finally, after some tests, Nafion ${ }^{\circledR}$ electrospraying was done at voltage equal $5 \mathrm{kV}$ RMS with $2.5 \mathrm{kV}$ DC component. Additional AC component eliminated the problem of droplets repulsing from quartz substrate almost completely.

The experimental configurations for both DC and $\mathrm{DC}+\mathrm{AC}$ electrospraying were the same. The solution source consisted of a $1 \mathrm{ml}$ syringe with a needle of the inner diameter equal to $0.2 \mathrm{~mm}$. The flow rate of the solution was about $1 \mathrm{ml} / \mathrm{h}$ and the needle to substrate the distance was approximately $3 \mathrm{~cm}$. The Nafion ${ }^{\circledR}$ solution in water and lower alcohols (5\% wt.) was obtained from the Sigma-Aldrich ${ }^{\circledR}$ company. The average molecular weight of Nafion ${ }^{\circledR}$ was $700000 \mathrm{amu}$. The solution was used in the electrospraying experiments without- and with several times dilution in ethyl alcohol. The coating thickness was controlled by adjusting the spray time and concentration of the solution. The examined coating was obtained from Nafion ${ }^{\circledR}$ solution twice diluted with ethyl alcohol and electrosprayed for 5 min.

Thermal vacuum evaporation was applied as a reference method for Nafion ${ }^{\circledR}$ deposition. The method is successfully used in SAW sensor fabrication (KAWALEC et al., 2008) but it requires sophisticated vacuum equipment and is very time consuming. Apart from that, Nafion ${ }^{\circledR}$ evaporation at the temperature above $200^{\circ} \mathrm{C}$ causes its partial degradation. In both cases, SAW sensors with shifts of the resonant frequency of about $100 \mathrm{kHz}$ according to uncoated SAW resonator were obtained.

The morphology of the Nafion ${ }^{\circledR}$ layers was analysed by means of a scanning electron microscope (Quanta 3D FEG SEM/FIB). In Figs. 4 and 5, SEM micrographs with the same magnification show the morphology of the polymer, one of them (Fig. 4) pre-
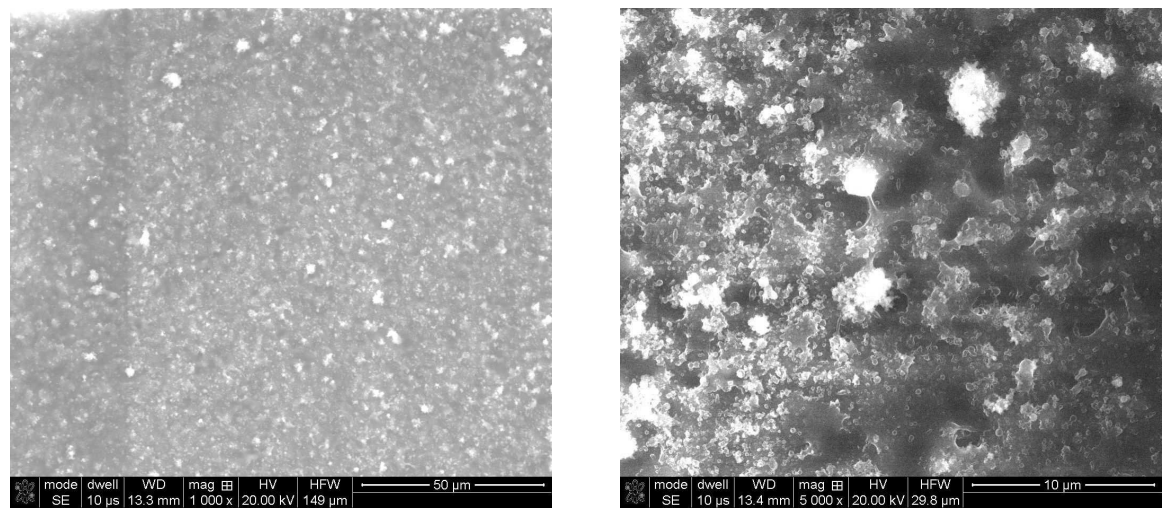

Fig. 4. SEM images of Nafion ${ }^{\circledR}$ deposited by means of electrospray.
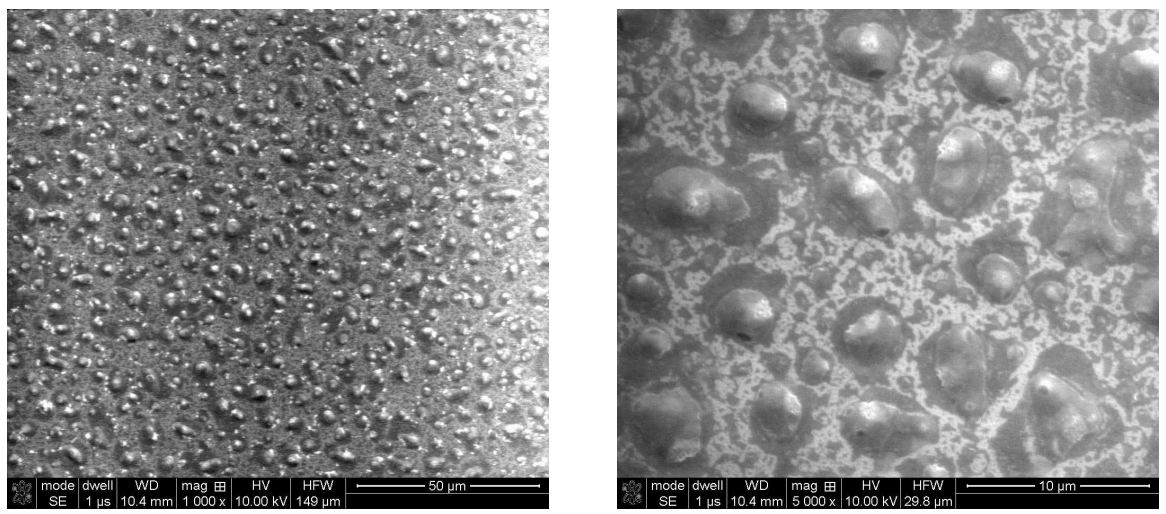

Fig. 5. SEM images of Nafion@ deposited by means of vacuum evaporation. 
pared by elecrospraying and the other one by vacuum thermal evaporation (Fig. 5). As it can be seen, the layer fabricated using the electrospray method covered the whole quartz surface, unlike the evaporated Nafion ${ }^{\circledR}$ which agglomerated into droplets. Formation of droplets is inducted by the high temperature at which evaporation and condensation polymer molecules proceeds. The electrosprayed Nafion ${ }^{\circledR}$ is characterised by a more developed area and it is porous, which reduces the limitations in mass transport.

It is easy to notice that the morphology of the electrosprayed layer is much more homogeneous when compared with the layer deposited by thermal sputtering.

\subsection{Sensor characteristics}

The responses of both sensors against humidity were collected at measurement setup presented in (JASEK et al., 2013). The appropriate concentration of the vapours was obtained by means of a mass flow controller set generated by the diffusion source. Likewise, water vapour generated in a bubbler was diluted in dry nitrogen. The frequency and amplitude responses of the sensors were measured using a self-made vector analyser described in detail in (JASEK et al., 2013).

Frequency characteristics of the SAW sensor, before and after the deposition of Nafion ${ }^{\circledR}$ film are presented in Fig. 6. The frequency increment in relation to $194 \mathrm{MHz}$ is represented on the horizontal axis.

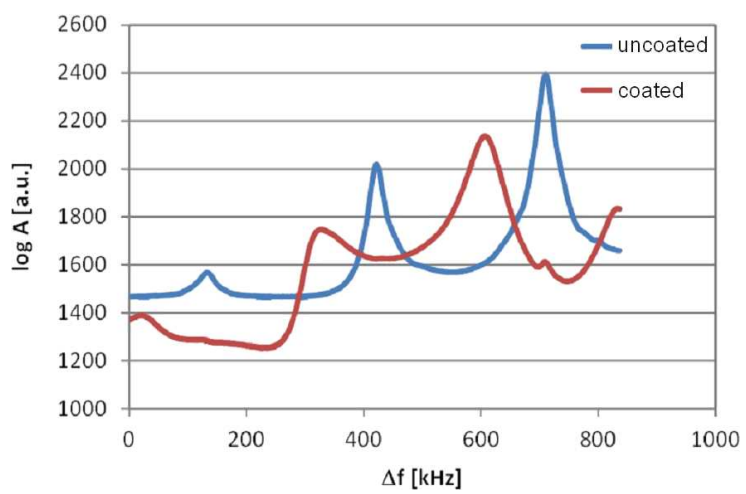

Fig. 6. Frequency characteristics of the SAW sensor, before and after Nafion ${ }^{\circledR}$ film deposition.

As the result of electrospraying we observe the shift of the resonance peaks of about $100 \mathrm{kHz}$ and decrease of their amplitudes. In all the measurements, variations of the frequency and amplitude of the highest peak at 194.61 MHz were recorded.

The normalised frequency responses of the electrosprayed and evaporated films are represented in Fig. 7.

As shown in Fig. 7, electrosprayed film provides a lower sensitivity and detection limit which is a little lower but also a shorter response time of the sensor. Faster response is the result of the larger area of the
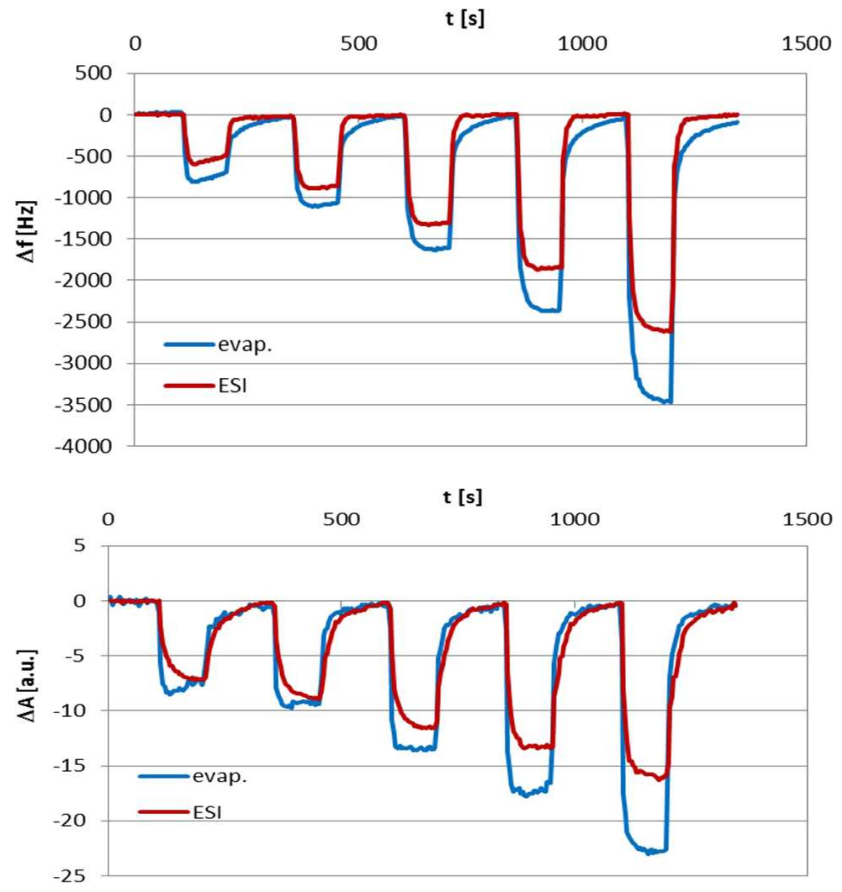

Fig. 7. Dynamic response of SAW sensors to humidity.

layer and easy access of the vapours to the polymer bulk. Slightly different sensitivity can result from the Nafion ${ }^{\circledR}$ structural changes in the course of the thermal evaporation. Nevertheless, properties of both sensors are very similar.

\section{Conclusions}

The electrospraying technology application to SAW sensor films deposition was presented. This technology has many advantages, such as simplicity, possibility of simultaneous deposition of mixtures of various materials (e.g. suspensions of polymer with metallic catalysers), and the possibility of precisely controlling the parameters of the deposition process. Moreover, because the process takes place at room temperature, it allows deposition of materials which are sensitive to high temperature.

The SAW humidity sensors with Nafion ${ }^{\circledR}$ layers served as an example here. For comparison purposes, two different deposition methods were applied: thermal evaporation and electrospraying. The layers obtained using the two methods were utterly different in respect to homogeneity but the sensing properties of the sensors utilising these layers were comparable. The advantages of the electrospraying lie in its simplicity and versatility.

\section{Acknowledgments}

This work was supported by the research projects PBS656, financed by the Polish Ministry of Sciences and Higher Education. 


\section{References}

1. Adhikari B., Majumdar S. (2004), Polymers in sensor applications, Progress in Polymer Science, 29, 7, 699-766, doi: 10.1016/j.progpolymsci.2004.03.002.

2. Bain C.D., Whitesides G.M. (1989), Modelling organic surfaces with self-assembled monolayers, Advanced Materials, 1, 4, 110-116, doi: 10.1002/adma.19890010403.

3. Benítez R., Soler J., Daza L. (2005), Novel method for preparation of PEMFC electrodes by the electrospray technique, Journal of Power Sources, 151, 108113.

4. Devkota J., Оhodnicki P.R., Greve D.W. (2017), SAW sensors for chemical vapors and gases, Sensors, 17, 801, doi: $10.3390 / \mathrm{s} 17040801$.

5. Di Natale C., Paolesse R., Macagnano A., Mantini A., Goletti C., D'AmicoA A. (1998), Characterization and design of porphyrins-based broad selectivity chemical sensors for electronic nose applications, Sensors and Actuators B, 52, 1-2, 162-168, doi: 10.1016/S0925-4005(98)00269-X.

6. Fernandez de la Mora J., Loscertales I.G. (1994), The current emitted by highly conducted Taylor cones, Journal of Fluid Mechanics, 260, 155-184, doi: $10.1017 /$ S0022112094003472.

7. Gañán-Calvo M. (1999), The surface charge in electrospraying: its nature and its universal scaling laws, Journal of Aerosol Science, 30, 863-872.

8. Harsanyi G. (1995), Polymer films in sensor applications, CRC Press, ISBN 9781566762014.

9. Hassmann K., Gould R.D. (1992), Structural studies of thermally evaporated thin films of copper phthalocyanine, Physica Status Solidi, 132, 91-101.

10. Jakubik W., Krzywiecki M., Maciak E., URBAŃCZYK M. (2012), Bi-layer nanostructures of CuPc and $P d$ for resistance-type and $S A W$-type hydrogen gas sensors, Sensors and Actuators B, 175, 255- 262, doi: 10.1016/j.snb.2012.10.056.

11. JAKUBiK W., URBAŃCZYK M., MACiAK E. (2009), $S A W$ hydrogen gas sensor based on $\mathrm{WO}_{3}$ and $\mathrm{Pd}$ nanostructures, Procedia Chemistry, 1, 1, 200-203, doi:10.1016/j.proche.2009.07.050.

12. Jasek K., Miluski W., Pasternak M. (2013), A new system for acoustoelectronic gas sensors analysis, Acta Physica Polonica A, 124, 3, 445-447.

13. Jasek K., Neffe S., Pasternak M. (2012), SAW sensor for mercury vapors detection, Acta Physica Polonica A, 122, 5, 825-828.

14. Johnson R.W., Hultqvist A., Bent S.F. (2014), A brief review of atomic layer deposition: from fundamentals to applications, Materials Today, 17, 5, 236246, doi: 10.1016/j.mattod.2014.04.026.

15. Kawalec A., Jasek K., Pasternak M. (2008), Measurements results of SAW humidity sensor with Nafion layer, The European Physical Journal Special Topics, 154, 1, 123-126, doi: 10.1140/epjst/e2008-00529-x.
16. Lamara T., Belmahi M., Elmazria O., Le Brizoual L., Bougdira J., RÉmy M., Alnot P. (2004), Freestanding CVD diamond elaborated by pulsedmicrowave-plasma for $\mathrm{ZnO}$ / diamond SAW devices, Diamond and Related Materials, 13, 581-584.

17. Lee Y.J., Kim H.B. Kim, Roh Y.R., Cho H.M., BAIK S. (1998), Development of SAW gas sensor for monitoring $\mathrm{SO}_{2}$ gas, Sensors and Actuators A, 64, 173178.

18. Luo W., Deng J., Fu Q., Zhou D., Hu Y., Gong S., ZHeNG Z. (2015), Nanocrystalline $\mathrm{SnO}_{2}$ film prepared by the aqueous sol-gel method and its application as sensing films of the resistance and $\mathrm{SAW} \mathrm{H}_{2} \mathrm{~S}$ sensor, Sensors and Actuators B, 217, 119-128, doi: 10.1016/j.snb.2014.10.078.

19. Martin S., Garcia-Ybarra P.L., Castillo J.L. (2010a), Electrospray deposition of catalyst layers with ultra-low Pt loadings for PEM fuel cells cathodes, Journal of Power Sources, 195, 2443-2449.

20. Martin S., Garcia-Ybarra P.L., Castillo J.L. (2010b), High platinum utilization in ultra-low Pt loaded PEM fuel cell cathodes prepared by electrospraying, International Journal of Hydrogen Energy, 35, 10446-10451.

21. Ogata S., Hatae T., Shoguchi K., Shinohara H. (1978), The dimensionless correlation of mean particle diameter in electrostatic atomization, International Chemical Engineering, 18, 3, 488-493.

22. Piqué, Auyeung R.C.Y., Stepnowski J.L., Weir D.W., Arnold C.B., McGill R.A., Chrisey D.B. (2003), Laser processing of polymer thin films for chemical sensor applications, Surface and Coatings Technology, 163-164, 293-299.

23. Raj V. B., Nimalb A.T., Parmarb Y., SharMAB M.U., Gupta V. (2012), Investigations on the origin of mass and elastic loading in the time varying distinct response of $Z n O S A W$ ammonia sensor, Sensors and Actuators B, 166-167, 576-585, doi: 10.1016/j.snb.2012.03.013.

24. Raj V.B., Singh H., Nimal A.T., Sharma M.U., Gupta V. (2013), Oxide thin films ( $\mathrm{ZnO}$, $\mathrm{TeO}_{2}$, $\mathrm{SnO}_{2}$, and $\mathrm{TiO}_{2}$ ) based surface acoustic wave (SAW) E-nose for the detection of chemical warfare agents, Sensors and Actuators B, 178, 636-647, doi: 10.1016/j.snb.2012.12.074.

25. RAYleigh R.S. (1882), On the equilibrium of liquid conducting masses charged with electricity, Philosophical Magazine Series, 14, 7, 184-186. doi: 10.1080/14786448208628425.

26. Roberts G. (1990), Langmuir-Blodgett films, Plenum, New York.

27. Rozhkova A., Prunet-Foch B., Vignes-Adler M. (2015), Star-like breakup of polymeric drops in electrical field, Journal of Non-Newtonian Fluid Mechanics, 226, 46-59, doi: 10.1016/j.jnnfm.2015.10.001.

28. Sarkar S., Levit N., Tepper G. (2006), Deposition of polymer coatings onto $S A W$ resonators using $A C$ electrospray, Sensors and Actuators B, 114, 756-761, doi: 10.1016/j.snb.2005.07.051. 
29. Soluch W. (2008), SAW synchronous multimode resonator with gold electrodes on quartz, IEEE Trans. Ultrason. Ferroelect. Freq. Contr., 55, 6, 1391-1393, doi: 10.1109/TUFFC.2008.803.

30. Vanotti M., Blondeau-Patissier V., MoutarLier V., Ballandras S. (2015), Analysis of palladium and yttrium-palladium alloy layers used for hydrogen detection with $S A W$ device, Sensors and Actuators B, 217, 30-35, doi: 10.1016/j.snb.2015.02.049.

31. Viespe C., Grigoriu C. (2013), SAW sensor based on highly sensitive nanoporous palladium thin film for hydrogen detection, Microelectronic Engineering, 108, 218-221, doi: 10.1016/j.mee.2012.12.001.

32. Zhou R., Schmeisser D., Göpel W. (1996), Mass sensitive detection of carbon dioxide by amino groupfunctionalized polymers, Sensors and Actuators B, 33, 188-193.

33. Zimmermann C., Rebière D., Déjous C., Pistré J., Chastaing E., Planade R. (2001), A love-wave gas sensor coated with functionalized polysiloxane for sensing organophosphorus compounds, Sensors and Actuators B, 76, 86-94. 